\title{
The impact of factors to profitability of some coal mining enterprises after vinacomin restructure project
}

\section{Trang Thu Pham *}

Faculty of Economics and Business Administration, Hanoi University of Mining and Geology, Vietnam

\begin{tabular}{|c|c|}
\hline ARTICLE INFO & ABSTRACT \\
\hline $\begin{array}{l}\text { Article history: } \\
\text { Received 10th Aug. } 2020 \\
\text { Revised 25th Sept. } 2020 \\
\text { Accepted 31 }\end{array}$ & $\begin{array}{l}\text { The article uses Dupont analysis to determine the factors affecting } \\
\text { profitability (ROE) of Vietnam coal mining enterprises and the regression } \\
\text { method to examine the impact of production capacity of short-term } \\
\text { assets, production capacity of long-term assets, production capacity of }\end{array}$ \\
\hline $\begin{array}{l}\text { Keywords: } \\
\text { Capital structure, } \\
\text { Mining companies, } \\
\text { Production capacity of long- } \\
\text { term assets, } \\
\text { Production capacity of short- } \\
\text { term assets, } \\
\text { ROE. }\end{array}$ & $\begin{array}{l}\text { costs and capital structure on the profitability of firms. The article uses } \\
\text { financial data collected from } 19 \text { coal mining companies of Vietnam } \\
\text { National Coal-Mineral Industries Holding Corporation during the period } \\
\text { of } 2015 \text { - 2018. The results show that production capacity of short-term } \\
\text { assets, production capacity of long-term assets, production capacity of } \\
\text { costs and capital structure positively impact profitability. The paper } \\
\text { suggests } 2 \text { ways to improve profitability: firstly, borrowing to invest in } \\
\text { technology will help coal mining enterprises improve their profitability; } \\
\text { secondly, improving production processes appropriately to take full } \\
\text { advantage of existing equipment capacity, thereby increasing } \\
\text { profitability. }\end{array}$ \\
\hline
\end{tabular}

Copyright @ 2020 Hanoi University of Mining and Geology. All rights reserved.

${ }^{*}$ Corresponding author

E-mail: spring83b@gmail.com

DOI: 10.46326/JMES.KTQT2020.13 


\title{
Nhân tố ảnh hưởng tới khả năng sinh lời của các doanh nghiệp khai thác than thuộc Tập đoàn công nghiệp Than-Khoáng sản Việt Nam sau tái cơ cấu
}

\author{
Phạm Thu Trang* \\ Khoa Kinh tế và Quản trị kinh doanh, Trường Đại học Mỏ - Địa chất, Việt Nam
}

THÔNG TIN BÀI BÁO $\quad$ TÓM TẮT

Quá trình:

Nhận bài 10/8/ 2020

Sửa xong 25/ 09/2020

Chấp nhận đăng 31/ 10/ 2020

Tù khóa:

Cơ cấu vốn,

Doanh nghiệp khai thác

than,

ROE,

Sức sản xuất của tài sản

ngắn hạn,

Sức sản xuất của tài sản dài hạn.
Bài báo sư dụng phương pháp phân tích Dupont để xác định các nhân tố ảnh hương tới khả năng sinh lời (ROE) của các doanh nghiệp khai thác than thuộc Tập đoàn công nghiệp than-khoáng sản Việt Nam (TKV) và phương pháp phân tích hồi quy để xem xét tác động của sức sản xuất của tài sản ngắn hạn, sức sản xuất của tài sản dài hạn, sức sản xuất của chi phí và cơ cấu vốn tới khả năng sinh lòi của các doanh nghiệp. Bài báo sử dụng số liệu tài chính thu thập từ 19 công ty khai thác than thuộc TKV trong giai đoạn 2015-2018 để phân tích. Kết quả nghiên cúu cho thấy, các nhân tố sức sản xuất của tài sản ngắn hạn, sức sản xuất của tài sản dại hạn, sức sản xuất của chi phí và cơ cấu vốn đều có quan hệ cùng chiều với khả năng sinh lời. Trong đó, súc sản xuất của chi phí là nhân tố có tác động manh nhất tới ROE, tiếp đến là sức sản xuất của tài sản dài hạn. Dựa trên kết quả nghiên cứu, tác giả đã phát hiện 2 gợ ý giúp các doanh nghiêp khai thác than thuộc TKV khu vực Quảng Ninh nâng cao khả năng sinh lời: một là, đầu tư vào công nghê (có thể bằng vốn vay) nhằm giảm chi phí tù̀ đó tăng khả năng sinh lời; hai là, cải tiến quy trình sản xuất hợp lý để tận dụng tối đa công suất thiết bị hiện có tùr đó giúp tăng khả năng sinh lời.

C 2020 Trường Đại học Mỏ - Địa chất. Tất cả các quyền được bảo đảm.

\section{Mở đầu}

Các doanh nghiệp khai thác than thuộc TKV khu vực Quảng Ninh đóng vai trò quan trọng trong việc đáp ứng nhu cầu than của cả nước. Tuy nhiên, trong những năm gần đây, các doanh nghiệp này phải đối mặt với nhiều khó khăn do điều kiện khai thác ngày càng xuống sâu, dẫn đến chi phí khai

\section{*Tác giả liên hệ}

E - mail: spring83b@gmail.com

DOI: 10.46326/JMES.KTQT2020.13 thác ngày càng tăng cao. Đặc biệt, giai đoạn 2015 $\div 2018$ là giai đoạn các doanh nghiệp khai thác than vừa mới hoàn thành quá trình tái cơ cấu với việc loại bỏ nhiều doanh nghiệp cấp 3, hoàn thành chuyển đổi nhiều công ty TNHH 1 thành viên thành các công ty chi nhánh trực thuộc TKV, thoái vốn ra khỏi các ngành nghề khác. Các doanh nghiệp khai thác than thuộc TKV khu vực Quảng Ninh buộc phải tìm kiếm các giải pháp khác nhau để nâng cao khả năng sinh lời, trong đó vay vốn đầu tư vào tài sản dài hạn và quản lý chặt chẽ chi phí là những biện pháp được các doanh nghiệp cân nhắc sử dụng. Bài báo sử dụng phương pháp 
phân tích hồi quy để đo lường mức độ tác động của quản lý tài sản và chi phí tới khả năng sinh lời (được đại diện bởi chỉ tiêu tỷ suất lợi nhuận trên vốn chủ sở hữu-ROE). Kết quả phân tích sẽ giúp các doanh nghiệp tìm ra các giải pháp nâng cao khả năng sinh lời của doanh nghiệp.

\section{Cơ sở lý luận của đề tài}

Nhận thức được tầm quan trọng của việc tìm ra giải pháp nâng cao khả năng sinh lời cho các doanh nghiệp khai thác than thuộc TKV khu vực Quảng Ninh trong giai đoạn sắp tới, bài viết đi sâu tìm hiểu nhằm xác định các nhân tố ảnh hưởng đến khả năng sinh lời của các doanh nghiệp này để đưa ra các giải pháp hữu hiệu nhằm cải thiện khả năng sinh lời.

\subsection{Khả năng sinh lòi của doanh nghiệp}

Khả năng sinh lợi là chỉ tiêu phản ánh mức lợi nhuận mà doanh nghiệp có thể thu được trên một đơn vị chi phí hay yếu tố đầu vào hay trên một đơn vị đầu ra phản ánh kết quả kinh doanh. Tùy vào mục đích sử dụng, mỗi nghiên cứu sẽ sử dụng những chỉ tiêu khác nhau để phản ánh khả năng sinh lời. Nhiều nghiên cứu sử dụng $\mathrm{ROE}$ để phản ánh khả năng sinh lời của doanh nghiệp. Sivathaasan (2013) đã tiến hành nghiên cứu các nhân tố ảnh hưởng đến khả năng sinh lời của tất cả các công ty sản xuất niêm yết trên sàn giao dịch chứng khoán Colombia, Sri Lanka từ năm 2008 đến năm 2012. Trong đó, khả năng sinh lời của các doanh nghiệp được đại diện bởi 2 chỉ tiêu ROE và tỷ suất sinh lời trên tổng tài sản (ROA) (Sivathaasan và nnk, 2013). Popa AlexandruEmil (2014) lựa chọn 2 chỉ tiêu ROE và tỷ suất sinh lời trên vốn đầu tư (ROIC) phản ánh khả năng sinh lời trong nghiên cứu về các nhân tố tài chính ảnh hưởng tới khả năng sinh lời của các doanh nghiệp nhỏ và vừa (Popa Alexandru-Emil, 2014). Gill Amarjit (2011) lựa chọn ROE phản ánh khả năng sinh lời trong nghiền cứu về tác động của cấu trúc vốn tới khả năng sinh lời của 272 doanh nghiệp niêm yết trên thị trường chứng khoán New York (Gill Amarjit và nnk, 2011). Lê Thị Nhu (2018) sử dụng các chỉ tiêu ROE, ROA, tỷ suất sinh lời trên doanh thu (ROS) để phản ánh khả năng sinh lời theo sổ sách (Lê Thị Nhu, 2018),... Như vậy, ROE là chỉ tiêu được hầu hết các nghiên cứu sử dụng như một chỉ tiều quan trọng nhất phản ánh khả năng sinh lời của doanh nghiệp.

\subsection{Các nhân tố ảnh hưởng tới khả năng sinh lò̀}

Với những mục đích nghiên cứu khác nhau, các nhà nghiên cứu đã đưa ra nhiều mô hình với các nhân tố khác nhau tác động tới khả năng sinh lời của doanh nghiệp. Sivathaasan (2013) đã nghiên cứu tác động của các nhân tố cấu trúc vốn, cấu trúc tài sản, quy mô công ty và tốc độ tăng trưởng đến khả năng sinh lời của doanh nghiệp (Sivathaasan và nnk, 2013). Popa Alexandru-Emil (2014) đã sử dụng các biến độclập như tỷ suất tài sản hưu hình, cơ hội tăng trưởng, tỷ lệ nợ dài hạn trên vốn chủ sở hữu, hệ số quay vòng tổng tài sản, hệ số khả năng thanh toán lãi vay để nghiên cứu tác động của chúng tới khả năng sinh lời (Popa AlexandruEmil, 2014). Gill Amarjit (2011) nghiên cứu tác động của các nhân tố nợ ngắn hạn, nợ dài hạn, tổng nợ, quy mô doanh nghiệp, tăng trưởng doanh thu, loại hình doanh nghiệp tới khả năng sinh lời (Gill Amarjit và nnk, 2011). Lê Thị Nhu (2018) nghiên cứu tác động của các biến cấu trúc nguồn vốn, cấu trúc tài sản, quy mô tài sản, tốc độ tăng trưởng doanh thu, sức sinh lời của tổng tài sản, tuổi của doanh nghiệp tới khả năng sinh lời (Lê Thị Nhu, 2018). Trần Thị Phương Thảo (2019) nghiên cứu tác động của các biến cấu trúc nguồn vốn, quy mô doanh nghiệp, tỷ trọng tài sản cố định trên tổng tài sản, tỷ lệ tăng trưởng doanh thu, tỷ lệ chi trả cổ tức, khả năng thanh toán ngắn hạn, tỷ lệ sở hữu của nhà nước, ngành tới hiệu quả kinh doanh của doanh nghiệp được đại diện bởi ROE và tỷ lệ giữa giá trị thị trường và giá trị sổ sách (Tobin's Q) (Trần Thị Phương Thảo, 2019).

Các doanh nghiệp khai thác than thuộc TKV khu vực Quảng Ninh hiện nay đang gặp rất nhiều khó khăn do hoạt động khai thác than tại khu vực Quảng Ninh đã diễn ra từ rất lâu (từ cuối thế kỷ 19) nên điều kiện khai thác ngày càng xuống sâu và ngày càng khó khăn hơn, giá thành khai thác ngày càng cao. Để có thể hoạt động kinh doanh có hiệu quả, các doanh nghiệp này buộc phải quản lý chi phí, quản lý hiệu quả sử dụng tài sản cũng như đảm bảo cơ cấu vốn một cách hợp lý. Tác giả đã sử dụng phương pháp phân tích tài chính Dupont để phát triển các nhân tố tác động tới hiệu quả kinh doanh của doanh nghiệp. Theo đó: 


$$
\begin{aligned}
& \mathrm{ROE} \quad=\frac{L N}{V C S H}=\frac{L N}{D T} * \frac{D T}{T S} * \frac{T S}{V C S H} \\
& =\frac{D T-C P}{D T} * \frac{D T}{T S N H+T S D H} * \frac{N P T+V C S H}{V C S H} \\
& =\left(1-\frac{1}{\frac{D T}{C P}}\right) * \frac{1}{\frac{1}{\frac{D T}{T S N H}+\frac{1}{T S D H}}} *\left(1+\frac{N P T}{V C S H}\right)
\end{aligned}
$$

Trong đó: DT-Doanh thu; CP-chi phí; LN-lợi nhuận; TS-tài sản; TSNH-tài sản ngắn hạn; TSDHtài sản dài hạn; VSCH-Vốn chủ sở hữu; NPT-Nợ phải trả.

Theo mô hình Dupont được tác giả phát triển, các nhân tố ảnh hưởng tới khả năng sinh lời của doanh nghiệp, bao gồm: sức sản xuất của chi phí; sức sản xuất của tài sản dài hạn; sức sản xuất của tài sản ngắn hạn, và cơ cấu nguồn vốn.

\section{Phương pháp nghiên cứu}

\subsection{Xây dụ̂ng mô hình}

Mô hình được xây dựng trên cơ sở bộ số liệu thu thập từ báo cáo tài chính của 19 doanh nghiệp khai thác than thuộc Tập đoàn Công nghiệp ThanKhoáng sản Việt Nam giai đoạn năm 2015-2018 (xem Bảng 5, lưu ý là đầu năm 2018 công ty than Hồng Thái sáp nhập vào công ty than Uông Bí nên năm 2018 chỉ còn 18 doanh nghiệp khai thác than). Trong đó, biến phụ thuộc là ROE, 4 biến độc lập là sức sản xuất của chi phí $\left(\mathrm{H}_{\mathrm{DT} / \mathrm{CP}}\right)$; sức sản xuất của tài sản dài hạn ( $\left.\mathrm{H}_{\mathrm{DT} / \mathrm{TSDH}}\right)$; sức sản xuất của tài sản ngắn hạn $\left(\mathrm{H}_{\mathrm{DT} / \mathrm{TSNH}}\right)$; hệ số nợ trên vốn chủ sở hữu $\left(\mathrm{H}_{\mathrm{No} / \mathrm{VCSH}}\right)$

Bài báo sử dụng phương pháp phân tích hồi quy mẫu nên mô hình sẽ có dạng:

$$
\begin{aligned}
& \mathrm{ROE}=\widehat{\beta_{0}}+\widehat{\beta_{1}} \mathrm{H}_{\mathrm{DT} / \mathrm{CP}+\widehat{\beta_{2}}} \mathrm{H}_{\mathrm{DT} / \mathrm{TSDH}}+\widehat{\beta_{3}} \mathrm{H}_{\mathrm{DT} / \mathrm{TSNH}}+\widehat{\beta_{4}} \mathrm{H}_{\mathrm{No} /} \\
& \text { vCSH}+\mathrm{ei}
\end{aligned}
$$

Trong đó: $\widehat{\beta_{0}}$ - Hệ số chặn; $\widehat{\beta_{1}}, \widehat{\beta_{2}}, \widehat{\beta_{3}}, \widehat{\beta_{4}}$ - lần lượt là các hệ số cho biết tác động của $\mathrm{H}_{\mathrm{DT} / \mathrm{CP}}$, $\mathrm{H}_{\mathrm{DT} / \mathrm{TSDH}}, \mathrm{H}_{\mathrm{DT} / \mathrm{TSNH}}, \mathrm{H}_{\mathrm{Noo} / \mathrm{VCSH}}$ tới ROE; ei- số dư trong mô hình hồi quy mẫu

- Sức sản xuất của chi phí ( $\left.\mathrm{H}_{\mathrm{DT} / \mathrm{CP}}\right)$ : sức sản xuất của chi phí cho biết một đồng chi phí doanh nghiệp bỏ ra kinh doanh sẽ tạo ra được bao nhiêu đồng doanh thu.

$$
\mathrm{H}_{\mathrm{DT} / \mathrm{CP}}=\frac{\text { Tổng doanh thu }}{\text { Tổng chi phí }}
$$

Trong đó: Tổng doanh thu=doanh thu thuần từ bán hàng và cung cấp dịch vụ+doanh thu từ hoạt động tài chính+thu nhập khác

Tổng chi phí =Giá vốn hàng bán+chi phí tài chính+chi phí bán hàng+chi phí quản lý doanh nghiệp+chi phí khác+chi phí thuế thu nhập doanh nghiệp hiện hành.

Giả thuyết $\mathrm{H}_{0} 1$ : sức sản xuất của chi phí và khả năng sinh lời có quan hệ cùng chiều.

- Sức sản xuất của tài sản ngắn hạn ( $\left.\mathrm{H}_{\mathrm{DT} / \mathrm{TSNH}}\right)$ : sức sản xuất của tài sản ngắn hạn cho biết một đồng tài sản ngắn hạn đưa vào hoạt động kinh doanh sẽ góp phần tạo ra được bao nhiêu đồng doanh thu.

$$
\mathrm{H}_{\text {DT/TSNH }}=\frac{\text { Tổng doanh thu }}{\text { Tà } i \text { sản ngắn hạn bình quân }}
$$

Trong đó: Tài sản ngắn hạn bình quân

$=$

Tài sản dài hạn đầu năm+tài sản dài hạn cuối năm $(5)$ 2

Giả thuyết $\mathrm{H}_{0} 2$ : sức sản xuất của tài sản ngắn hạn và khả năng sinh lời có quan hệ cùng chiều

- Sức sản xuất của tài sản dài hạn $\left(\mathrm{H}_{\mathrm{DT} / \mathrm{TSDH}}\right)$ : sức sản xuất của tài sản dài hạn cho biết một đồng tài sản dài hạn đưa vào hoạt động kinh doanh sẽ góp phần tạo ra được bao nhiêu đồng doanh thu.

$$
\mathrm{H}_{\mathrm{DT} / \mathrm{TSDH}}=\frac{\text { Tổng doanh thu }}{\text { Tà } i \text { sản dài hạn bình quân }}
$$

Trong đó: Tài sản dài hạn bình quân

$=$

Tài sản dài hạn đầu năm+tài sản dài hạn cuối năm

Giả thuyết $\mathrm{H}_{0} 3$ : sức sản xuất của tài sản dài hạn và khả năng sinh lời có quan hệ cùng chiều.

- Cơ cấu nguồn vốn hay hệ số nợ trên vốn chủ Sở hữu $\left(\mathrm{H}_{\mathrm{nơ} / \mathrm{VCSH}}\right)$ : Việc vay nợ sẽ giúp doanh nghiệp có thêm được lợi nhuận từ sự chênh lệch giữa doanh thu thu thêm từ vốn vay với chi phí bỏ ra để có được đồng vốn vay đó, nhờ đó mà làm tăng tỷ suất lợi nhuận trên vốn chủ sở hữu của doanh nghiệp (ROE). Hiện nay, hầu hết các doanh nghiệp trên thế giới nói chung và các doanh nghiệp Việt Nam nói riêng đều sử dụng nợ như một đòn bẩy tài chính để ra tăng khả năng sinh lời và phân tán rủi ro cho vốn đầu tư của chủ sở hữu.

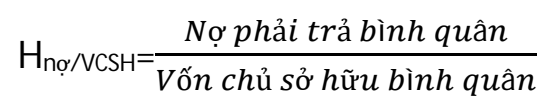


Trong đó: Nợ phải trả bình quân = Nợ phải trả đầu năm+nợ phải trả cuối năm

Vốn chủ sở hữu bình quân

Vốn chủ sở hữu đầu năm+vốn chủ sở hữu cuối năm 2

Giả thuyết $\mathrm{H}_{0} 4$ : Hệ số nợ trên vốn chủ sở hữu và khả năng sinh lời có quan hệ cùng chiều.

\subsection{Kết quả nghiên cúru}

Theo Bảng 1, ROE bình quân của các doanh nghiệp khai thác than thuộc TKV khu vực Quảng Ninh trong giai đoạn 2015-2018 là 0,063, có nghĩa là chủ sở hữu cứ bỏ ra 1 đồng vốn đầu tư thì sẽ thu lại được 0,063 đồng lợi nhuận sau thuế. Trong giai đoạn 2015-2018, Sức Sản xuất của chi phí ( $\left.\mathrm{H}_{\mathrm{DT} / \mathrm{CP}}\right)$ bằng 1,01 cho biết một đồng chi phí bỏ vào kinh doanh, các doanh nghiệp sẽ tạo ra được 1,01 đồng doanh thu. Sức sản xuất của tài sản ngắn hạn bằng 7,08 thể hiện rằng cứ đầu tư 1 đồng tài sản ngắn hạn vào kinh doanh thì sẽ góp phần giúp doanh nghiệp thu được 7,08 đồng doanh thu. Sức sản xuất của tài sản dài hạn cho biết doanh nghiệp cứ đầu tư 1 đồng vào tài sản dài hạn thì sẽ góp phần tạo ra 1,96 đồng doanh thu. Hệ số nợ trên vốn chủ sở hữu cho biết cứ 1 đồng vốn chủ sở hữu bỏ ra kinh doanh doanh nghiệp phải sử dụng thêm 4,95 đồng nợ phải trả, hay trong 1 đồng vốn doanh nghiệp đưa vào kinh doanh thì có 0,83 đồng nợ phải trả.

Kết quả trong Bảng 2 cho thấy, mô hình hồi quy cho kết quả là phù hợp khi hệ số tương quan bội của mô hình xấp xỉ 0,897 nên mô hình được coi là thích hợp. Hệ số tương quan (R square) cho biết 80,5\% sự biến động của ROE là do các yếu tố sức sản xuất của chi phí $\left(\mathrm{H}_{\mathrm{DT} / \mathrm{CP}}\right)$; sức sản xuất của tài sản dài hạn $\left(\mathrm{H}_{\mathrm{DT} / \mathrm{TSDH}}\right)$; sức sản xuất của tài sản ngắn hạn ( $\left.\mathrm{H}_{\mathrm{DT} / \mathrm{TSNH}}\right)$; hệ số nợ trên vốn chủ sở hữu $\left(\mathrm{H}_{\mathrm{Nợ} / \mathrm{VCSH}}\right)$ gây ra. Hệ số tương quan điều chỉnh (Adjusted $\mathrm{R}$ square) là 79,4\% gần bằng với hệ số tương quan chứng tỏ các biến đều quan trọng. Kiểm định Durbin-Watson cho kết quả bằng 2,211 $(1<\mathrm{d}<3)$ cho thấy mô hình không có hiện tượng tự tương quan.

Giá trị Sig. của kiểm định $\mathrm{F}$ là nhỏ hơn 0,05 (Bảng 3) chứng tỏ mô hình hồi quy tuyến tính xây dựng được phù hợp với tổng thể.

Theo Bảng 4, Hệ số VIF của các nhân tố đều nhỏ hơn 2 do vậy không có đa cộng tuyến xảy ra. Giá trị Sig. của kiểm định $t$ từng biến độc lập cho kết quả của các biến sức sản xuất của chi phí, sức sản xuất của tài sản dài hạn nhỏ hơn 0,05 có nghĩa là các biến số này có ý nghĩa thống kê. Giá trị sig của kiểm định $\mathrm{t}$ các biến sức sản xuất của tài sản ngắn hạn, cơ cấu vốn lớn hơn 0,05 chứng tỏ mối quan hệ giữa sức sản xuất của tài sản ngắn hạn và cơ cấu vốn với ROE không có ý nghĩa thống kê.

Từ kết quả phân tích, mô hình tác động của các nhân tố ảnh hưởng tới ROE được viết lại là:

$\mathrm{ROE}=5,907+5,866 \cdot \mathrm{H}_{\mathrm{DT} / \mathrm{CP}}+7,203 \cdot 10^{-5}$ . $\mathrm{H}_{\mathrm{DT} / \mathrm{TSNH}}+0,015 . \mathrm{H}_{\mathrm{DT} / \mathrm{TSDH}}+0,004 . \mathrm{H}_{\mathrm{no} / \mathrm{VCSH}}+\mathrm{C}_{\mathrm{i}}$

Kết quả mô hình cho thấy, 4 giả thuyết được đưa ra đều phù hợp. Các nhân tố ảnh hưởng đều có mối quan hệ cùng chiều với ROE. Trong trường hợp các yếu tố khác không đổi, khi $\mathrm{H}_{\mathrm{DT} / \mathrm{CP}}$ tăng lên 1 đơn vị thì ROE sẽ tăng lên 5,866 đơn vị; khi $\mathrm{H}_{\mathrm{DT} / \mathrm{TSDH}}$ tăng lên 1 đơn vị thì ROE tăng lên 0,015 đơn vị; khi $\mathrm{H}_{\text {nơ } / \mathrm{vCSH}}$ tăng lên 1 đơn vị thì $\mathrm{ROE}$ sẽ tăng lên 0,004 đơn vị; và khi $\mathrm{H}_{\mathrm{DT} / \mathrm{TSNH}}$ tăng lên 1 đơn vị thì ROE sẽ tăng lên 7,203.10-5 đơn vị.

Bảng 1. Thống kê mô tả.

\begin{tabular}{|c|c|c|c|}
\hline Biến & Bình quân & $\begin{array}{c}\text { Độ lệch } \\
\text { chuẩn }\end{array}$ & $\begin{array}{c}\text { Số quan } \\
\text { sát }\end{array}$ \\
\hline $\mathrm{ROE}$ & 0,063 & 0,142 & 75 \\
\hline $\mathrm{H}_{\mathrm{DT} / \mathrm{CP}}$ & 1,01 & 0,021 & 75 \\
\hline $\mathrm{H}_{\mathrm{DT} / \mathrm{TSNH}}$ & 7,08 & 2,987 & 75 \\
\hline $\mathrm{H}_{\mathrm{DT} / \mathrm{TSDH}}$ & 1,96 & 1,334 & 75 \\
\hline $\mathrm{H}_{\mathrm{nợ} / \mathrm{VCSH}}$ & 4,95 & 2,478 & 75 \\
\hline
\end{tabular}

Bảng 2. Tóm tắt mô hình.

\begin{tabular}{|c|c|c|c|c|c|}
\hline & 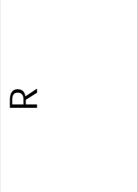 & 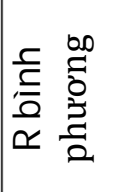 & 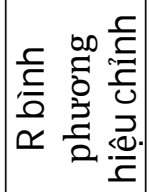 & 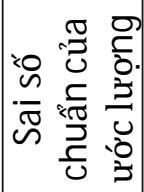 & 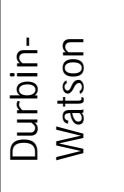 \\
\hline 1 & $0,897 \mathrm{a}$ & 0,805 & 0,794 & 0,0646 & 2,211 \\
\hline
\end{tabular}

Bảng 3. Phân tích ANOVAa .

\begin{tabular}{|l|c|r|c|c|c|}
\hline Mô hình & $\begin{array}{c}\text { Tổng } \\
\text { bình } \\
\text { phương }\end{array}$ & Df & $\begin{array}{c}\text { Bình } \\
\text { phương } \\
\text { trung } \\
\text { bình }\end{array}$ & F & Sig. \\
\hline Regression & 1,203 & 4 & 9,301 & 72,12 &, $000^{b}$ \\
\hline Residual & 0,292 & 70 & 0,004 & & \\
\hline Total & 1,495 & 74 & & & \\
\hline
\end{tabular}


Bảng 4. Các hệ số.

\begin{tabular}{|c|c|c|c|c|c|c|c|}
\hline \multirow[t]{2}{*}{ Mô hình } & \multicolumn{2}{|c|}{ Hệ số hồi quy } & Hệ & \multirow[t]{2}{*}{$\mathrm{T}$} & \multirow[t]{2}{*}{ Sig. } & \multicolumn{2}{|c|}{ Thống kê đa cộng tuyến } \\
\hline & B & Sai số chuẩn & Beta & & & Tolerance & VIF \\
\hline (Constant) & $-5,907$ & 0,356 & & $-16,601$ & 0,000 & & \\
\hline $\mathrm{H}_{\mathrm{DT} / \mathrm{CP}}$ & 5,866 & 0,353 & 0,881 & 16,618 & 0,000 & 0,992 & 1,008 \\
\hline $\mathrm{H}_{\mathrm{DT} / \mathrm{TSNH}}$ & 7,203E-005 & 0,003 & 0,002 & 0,028 & 0,978 & 0,950 & 1,052 \\
\hline $\mathrm{H}_{\mathrm{DT} / \mathrm{TSDH}}$ & 0,015 & 0,007 & 0,138 & 2,232 & 0,029 & 0,733 & 1,364 \\
\hline $\mathrm{H}_{\mathrm{n} \sigma / \mathrm{VCSH}}$ & 0,004 & 0,004 & 0,063 & 1,009 & 0,316 & 0,707 & 1,415 \\
\hline
\end{tabular}

Tuy nhiên, để xem xét tác động của các nhân tố tới sự thay đổi của ROE, hệ số hồi quy chuẩn hóa Beta sẽ cho kết quả chuẩn xác hơn. Hệ số hồi quy chuẩn hóa của sức sản xuất của chi phí (Doanh thu trên chi phí) là nhân tố có ảnh hưởng cao nhất tới sự thay đổi của ROE với hệ số Beta là 0,881 . Như vậy, việc quản lý tốt chi phí đang có ảnh hưởng tích cực tới hiệu quả kinh doanh của doanh nghiệp, các doanh nghiệp kiểm soát càng tốt chi phí sẽ có tác động mạnh mẽ tới khả năng tăng khả năng sinh lời của doanh nghiệp. Tiếp theo sức sản xuất của tài sản dài hạn sẽ đem lại tác độngyếu hơn so với sức sản xuất của chi phí mặc dù mức độ tác động cũng tương đối cao (hệ số Beta $=0,138$ ). Và có ảnh hưởng thấp hơn so với hai biến trên là cơ cấu vốn
(Beta $=0,063)$ và sức sản xuất của tài sản ngắn hạn (Beta $=0,002)$.

\section{Bàn luận kết quả nghiên cứu và đề xuất}

Kết quả nghiên cứu cho thấy, việc tăng cường quản lý và nâng cao hiệu quả quản lý chi phí sẽ có tác động mạnh nhất tới hiệu quả kinh doanh của các doanh nghiệp khai thác than thuộc TKV khu vực Quảng Ninh. Qua nghiên cứu số liệu của các doanh nghiệp khai thác than thuộc TKV khu vực Quảng Ninh (Bảng 5), những doanh nghiệp có tỷ suất lợi nhuận trên vốn chủ sở hữu lớn nhất là những doanh nghiệp có sức sản xuất của chi phí cao nhất, đó là các công ty cổ phần than Hà Lầm

Bảng 5. Thống kê giá trị bình quân của các biến nghiên cứu.

\begin{tabular}{|c|c|c|c|c|c|c|}
\hline STT & Đơn vị & \multicolumn{5}{|c|}{ Bình quân giai đoạn 2015-2018 } \\
\hline & & $\mathbf{H}_{\text {DT/CP }}$ & H DT/TSNH $_{\text {DS }}$ & $\mathbf{H}_{\text {DT/TSDH }}$ & $\mathbf{H}_{\mathrm{nọ} / \mathrm{VCSH}}$ & ROE \\
\hline 1 & Cty than Uông Bí & 0,999 & 5,146 & 1,395 & 1,803 & 0,004 \\
\hline 2 & Công ty Than Hồng Thái & 0,751 & 5,390 & 1,652 & 3,208 & 0,008 \\
\hline 3 & Cty than Mạo Khê & 1,006 & 5,052 & 1,492 & 3,407 & 0,032 \\
\hline 4 & Cty than Thống Nhất & 1,005 & 9,367 & 1,427 & 4,955 & 0,039 \\
\hline 5 & Cty than Dương Huy & 0,990 & 10,039 & 1,601 & 3,590 & $-0,064$ \\
\hline 6 & Cty CP than Mông Dương & 1,009 & 4,648 & 1,842 & 4,354 & 0,061 \\
\hline 7 & Cty than Khe Chàm & 0,992 & 9,308 & 0,692 & 7,028 & $-0,039$ \\
\hline 8 & Cty than Quang Hanh & 0,998 & 10,625 & 1,549 & 7,519 & $-0,045$ \\
\hline 9 & Cty than Hạ Long & 1,008 & 5,892 & 1,191 & 7,359 & 0,065 \\
\hline 10 & Cty CP than Hà Lầm & 1,022 & 8,961 & 0,785 & 11,584 & 0,194 \\
\hline 11 & Cty than Hòn Gai & 0,996 & 5,087 & 1,827 & 6,330 & $-0,011$ \\
\hline 12 & Cty CP than Vàng Danh & 1,016 & 5,833 & 1,561 & 4,751 & 0,105 \\
\hline 13 & Cty CP than Tây Nam Đá Mài & 1,030 & 10,926 & 1,723 & 5,554 & 0,178 \\
\hline 14 & Cty CP than Núi Béo & 1,046 & 2,715 & 1,129 & 3,684 & 0,157 \\
\hline 15 & Cty CP than Cọc Sáu & 1,011 & 7,512 & 2,932 & 3,518 & 0,092 \\
\hline 16 & Cty CP than Đèo Nai & 1,012 & 7,546 & 3,359 & 2,221 & 0,093 \\
\hline 17 & Cty CP than Cao Sơn & 1,008 & 7,274 & 2,985 & 5,941 & 0,117 \\
\hline 18 & Cty CP than Hà Tu & 1,016 & 6,302 & 6,332 & 1,568 & 0,131 \\
\hline 19 & Cty than Nam Mẫu & 1,015 & 5,134 & 1,308 & 5,272 & 0,109 \\
\hline
\end{tabular}


$(19,4 \%)$, công ty cổ phần than Tây Nam Đá Mài $(17,8 \%)$ và công ty cổ phần than Núi Béo $(15,7 \%)$. Mặc dù có sức sản xuất của chi phí cao nhưng công ty cổ phần than Hà Lầm và công ty cổ phần than Núi Béo là hai trong số các công ty có sức sản xuất của tài sản dài hạn thấp nhất. Trong giai đoạn vừa qua, cả hai công ty cổ phần than Hà Lầm và công ty cổ phần than Núi Béo đã đầu tư nhiều vào tài sản cố định, công nghệ nhằm xây dựng hệ thống khai thác hầm lò cơ giới hóa hiện đại. Chính vì đầu tư lớn vào tài sản cố định, công nghệ nên 2 công ty có sức sản xuất của tài sản dài hạn thấp. Tuy nhiên, nhờ đầu tư vào tài sản cố định và công nghệ mà hiệu quả sử dụng chi phí tăng và giúp tăng khả năng sinh lời của các doanh nghiệp này. Không giống công ty cổ phần than Hà Lầm đã là doanh nghiệp khai thác than Hâm Lò nhiều năm, công ty cổ phần than Núi Béo đang chuyển dần sang khai thác hầm lò nên chú trọng đầu tư máy móc thiết bị và công nghệ, công ty cổ phần than Tây Nam Đá Mài vẫn chủ yếu khai thác than lộ thiên. Để gia tăng hiệu quả kinh doanh, công ty Tây Nam Đá Mài đã tích cực bố trí sản xuất hợp lý, tạo mọi điều kiện để thiết bị hoạt động đảm bảo và nâng cao công suất thiết bị, tổ chức hoạt động kiểm tra và giám sát an toàn lao động, vệ sinh lao động thường xuyên,... nhờ đó mà công ty có được khả năng sinh lời cao trong giai đoạn $2015 \div 2018$.

Kết quả nghiên cứu đã đưa ra 2 gợi ý để nâng cao khả năng sinh lời của các doanh nghiệp khai thác than thuộc TKV là: (1) đầu tư vào công nghệ nhằm tăng hiệu quả kinh doanh và kiểm soát tốt chi phí; (2) tiếp tục cải tiến quy trình sản xuất hợp lý hơn, tạo điều kiện để tận dụng tối đa công suất thiết bị và kiểm soát tốt an toàn lao động.

\section{Những đóng góp của tác giả}

Phạm Thu Trang: Đóng góp mới vào việc xây dựng mô hình nghiên cứu các nhân tố tác động tới khả năng sinh lời bằng phương pháp Dupont và sử dụng bộ số liệu lấy từ báo cáo tài chính của các doanh nghiệp khai thác than để làm rõ mức độ tác động của từng nhân tố tới khả năng sinh lời của các doanh nghiệp này.

\section{Tài liệu tham khảo}

Gill Amarjit, Nahum Biger và Neil Mathur, (2011). The effect of capital structure on profitability: Evidence from the United States, Tạp chí
International Journal of Management, Số 28(4),tr.3.

Sivathaasan N, R Tharanika, M Sinthuja và V Hanitha, 2013. Factors determining profitability: A study of selected manufacturing companies listed on Colombo Stock Exchange in Sri Lanka, Tạp chí European Journal of Business and management, Số 5(27),tr: 99-108.

Popa Alexandru-Emil và Radu Ciobanu, (2014). The financial factors that influence the profitability of SMEs, Tạp chí International Journal of Academic Research in Economics and Management Sciences, Số 3(4),tr.: 177.

Lê Thị Nhu, 2018. Phân tích môi quan hệ giũa cấu trúc tài chính vói khả năng sinh lợ trong các công ty xây dựng niêm yêt trên thị trường chứng khoán Việt Nam, Luận án tiến sĩ kinh tế, Trường Đại học Kinh tế Quốc dân.

Trần Thị Phương Thảo,( 2019).Ảnh hưởng của cơ cấu vốn đến hiệu quả kinh doanh của các công ty cổ phần niêm yết trên thị trường chứng khoán Việt Nam, Luận án tiến sĩ kinh tế, Trường Đại học Thương Mại. 